\title{
Integração entre a Estratégia Saúde da Família e o Centro de Atenção Psicossocial
}

\author{
Integration between the Family Health Strategy and the \\ Psychosocial Care Center
}

\author{
Nayara Silva Borges', Luiz Antonio Teixeira² \\ 'Autora para correspondência. Universidade Federal do Espírito Santo. Vitória, Espírito Santo, Brasil. \\ ORCID: 0000-0002-0030-1327.nanysborges@hotmail.com \\ ${ }^{2}$ Fundação Oswaldo Cruz - Fiocruz. Rio de Janeiro, Rio de Janeiro, Brasil. ORCID: 0000-0001-8871-0928. luiztei3@gmail.com
}

RESUMO | OBJETIVO: Identificar as percepções e práticas dos profissionais do Centro de Atenção Psicossocial e da Estratégia Saúde da Família a respeito da integração desses setores. MÉTODO: Trata-se de um estudo exploratório descritivo de natureza qualitativa, em que os profissionais foram entrevistados através de roteiro estruturado, e utilizou-se o método de análise de conteúdo segundo Bardin. RESULTADOS: A partir dos achados, observamos que entre os muitos desafios que impossibilitam que o cuidado em saúde mental aconteça a partir da Estratégia Saúde da Família, destaca-se a ausência de um apoio matricial por parte da equipe do Núcleo de Apoio a Saúde da Família. CONCLUSÃO: É de suma importância a implementação de estratégias que visem essa integração, considerando sua importância para a efetivação do cuidado integral em saúde mental.

DESCRITORES: Saúde mental. Atenção primária à saúde. Estratégia saúde da família. Integração. Articulação.

\begin{abstract}
OBJECTIVE: To identify the perceptions and practices of the professionals of the Psychosocial Care Centers and the Family Health Strategy about the integration of these sectors. METHOD: This is an exploratory descriptive study of a qualitative nature, in which the professionals were interviewed through a structured script, and the Bardin content analysis method was used. RESULTS: Based on the findings, we observed that among the many challenges that make it impossible for mental health care to occur from the Family Health Strategy, the lack of a matrix support by the Family Health Support Units. CONCLUSION: It is essential to implement strategies aimed at this integration, considering its importance for the implementation of integral care in mental health.
\end{abstract}

KEYWORDS: Mental health. Primary health care. Family health strategy. Integration. Articulation. 


\section{Introdução}

Na perspectiva histórica, as pessoas com transtorno psiquiátrico foram tratadas como loucas e trancafiadas em manicômios e outros tipos de asilos, sendo afastadas do seu convívio familiar e social. Essas instituições muito mais que prestar assistência, buscavam a remoção dos considerados "loucos" da sociedade como forma de proteção à população, purificação e limpeza das cidades'.

No manicômio, o tratamento aos portadores de transtorno mental se dava a partir de medidas punitivas. Os pacientes eram submetidos à eletrochoques, celas-fortes, proibições, medicamentos em quantidades excessivas, uma série de outras formas de violências e medidas que evidenciam maus tratos, e não cuidado à saúde ${ }^{2}$.

No Brasil, a transformação desse modelo de exclusão para um modo de cuidar territorial, de forma com que a pessoa com transtorno mental tenha seu direito de viver como cidadão e presente na sociedade recebe o nome de Reforma Psiquiátrica. Esse processo se dá a partir da Reforma Sanitária, iniciada no final dos anos 70 , que buscava melhorias nas condições de vida da população, dando-se início a problematização sobre o modo de cuidar e tratar esses indivíduos.

A Reforma Psiquiátrica no Brasil corresponde a um processo longo, complexo, que ainda está em desenvolvimento, pois envolve muito mais que o fim dos manicômios, caracterizando-se como uma mudança na forma de tratar, falar, cuidar e, sobretudo, na forma de pensar em relação aos portadores de doença mental ${ }^{2}$. Por ter seu início com o processo de Reforma Sanitária, incorporou os seus princípios e diretrizes, como a universalidade, integralidade, descentralização e participação popular ${ }^{3}$.

No contexto de Reforma Psiquiátrica foram criados os Centros de Atenção Psicossocial (CAPS), com uma proposta de inserção do portador de transtorno mental na sociedade e, resgate de sua autonomia, cidadania e vínculo familiar. Esses centros se caracterizam como locais abertos, onde os usuários passam o dia e recebem um tratamento que não se baseia em isolamento e medicação, como era estabelecido nos manicômios. $O$ processo de fim dos manicômios e criação dos CAPS recebeu o nome de desinstitucionalização em saúde mental ${ }^{4}$.

A partir da Reforma Sanitária surgiu o Programa Saúde da Família (PSF), convertida em 2006 em Estratégia Saúde da Família (ESF), hoje entendida como porta de entrada ao sistema de saúde, inclusive daqueles que demandam cuidados em saúde mental. Os profissionais da ESF estabelecem com usuários uma relação de vínculo e devem estar sempre disponíveis como ouvintes e cuidadores desses usuários 5 .

Estudos sobre a ESF mostram que para o alcance da qualidade da atenção a pessoa com transtorno mental, é fundamental uma integração das ações do CAPS com a Atenção Básica (AB), mas especificamente a $E S F$, uma vez que a única forma de se obter um cuidado integral é através da articulação de diferentes níveis de atenção à saúde ${ }^{4}$.

A articulação em redes de saúde, sobretudo em saúde mental, com ênfase no CAPS e na ESF, consiste em uma estratégia fundamental para o alcance de um cuidado que esteja de acordo com os princípios da Reforma Sanitária e Reforma Psiquiátrica. Embora os estudos voltados para o trabalho integrado venham ganhando força nos últimos anos, observa-se que ainda existe uma lacuna neste campo de conhecimento, visto que os problemas que envolvem a articulação em redes ainda se fazem presentes dificultando o cuidado compartilhado, necessário para a integralidade do cuidado.

Dessa forma, objetiva-se identificar as percepções e práticas dos profissionais do CAPS e da ESF a respeito da integração desses setores, visto que esta integração potencializaria a integralidade do cuidado. Acredita-se que desta maneira as limitações possam ser identificadas, e que o cuidado em saúde mental venha a ser prestado a partir de um cuidado compartilhado entre diferentes níveis de atenção à saúde.

\section{Métodos}

Trata-se de uma pesquisa exploratória descritiva com abordagem qualitativa realizada no município de Bom Jesus do Itabapoana, Rio de Janeiro, 
Brasil. Bom Jesus do Itabapoana é um município de pequeno porte do estado do Rio de Janeiro, localizado na mesorregião noroeste fluminense. De acordo com o Censo Demográfico do IBGE (2010) a população total do município é de 35.384 de habitantes. Possui uma área de 598,84 quilômetros quadrados, subdividida com os 09 distritos de Bom Jesus do Itabapoana, Calheiros, Carabuçu, Mutum, Usina Santa Maria, Usina Santa Izabel, Pirapetinga, Barra de Pirapetinga, Rosal e Serrinha.

Atualmente a cobertura de implantação da ESF corresponde a $96 \%$ do município, com um total de 08 Unidades de AB localizadas na sede e 09 nos distritos. As equipes são formadas basicamente por médicos, enfermeiros, técnicos de enfermagem e agentes comunitários de saúde. O Município possui uma unidade de CAPS, que atende todos os casos de transtorno mental, criança/adolescente, e casos de álcool e drogas. Dentre a equipe do CAPS com nível superior, um médico clínico geral, um médico psiquiatra, uma nutricionista, duas enfermeiras, duas psicólogas, duas terapeutas ocupacionais, uma assistente social, um farmacêutico. O Município conta ainda com uma equipe de Núcleo de Apoio à Saúde da Família (NASF), composta por duas fonoaudiólogas, uma nutricionista, dois fisioterapeutas, uma psicóloga, uma assistente social e uma educadora física.

A pesquisa seguiu os seguintes critérios de inclusão: ser profissional com formação universitária atuante do CAPS, NASF, e ESF do município. Foram realizadas 39 entrevistas, sendo 24 de profissionais que compõem a ESF, 08 oriundas de profissionais do CAPS e 07 do NASF. Todos os profissionais que se enquadraram nos critérios de inclusão foram convidados a participar da pesquisa. Das entrevistas realizadas no âmbito da ESF, 13 foram enfermeiros e 11 foram de médicos. Foi entrevistado ao menos um profissional de cada UBS, sendo este o enfermeiro. $O$ número de enfermeiros entrevistados é menor que o número de ESF no município pelo fato de que por vezes o mesmo enfermeiro atua em duas ou mais Unidades.

Em razão de existirem apenas uma unidade CAPS e uma equipe de NASF no município, objetivou-se a totalidade dos profissionais que se enquadrassem nos critérios de inclusão da pesquisa, entretanto isso não foi possível em razão de recusa ou férias do profissional no período de coleta das entrevistas. Das entrevistas realizadas pelos profissionais do
CAPS foram duas psicólogas, uma enfermeira, um médico psiquiatra, uma assistente social, duas terapeutas ocupacionais e um farmacêutico. Já as entrevistas obtidas pela equipe do NASF foram de duas fonoaudiólogas, uma nutricionista, dois fisioterapeutas, uma psicóloga e uma assistente social.

A fim de identificar as percepções e práticas dos profissionais do CAP e da ESF a respeito da integração desses setores, e partindo do pressuposto de que a integração é a chave para a consolidação dos princípios da Reforma Sanitária e Reforma Psiquiátrica, realizou-se entrevistas mediante roteiro estruturado.

Os dados foram analisados a partir da análise de conteúdo segundo Bardin ${ }^{6}$. A partir da leitura foram criadas categorias que procuraram sintetizar as percepções dos profissionais que atuam nesses setores a respeito do trabalho integrado em saúde mental.

A pesquisa foi aprovada pelo parecer substanciado do CEP sob número 1.789.737.

\section{Resultados e discussão}

Os resultados da pesquisa demonstram que existe pouco conhecimento por parte dos profissionais da ESF em relação à demanda de pessoas com transtorno mental nos serviços. Observamos que muitas vezes tais profissionais não conhecem a magnitude epidemiológica dos problemas mentais, e por isso não conseguem compreender o seu papel no cuidado a esse paciente, transferindo a responsabilidade do cuidado ao centro especializado. Sendo assim, um grande entrave consiste na não responsabilização por essa demanda por parte da $A B$, que transferem todo cuidado ao CAPS.

De forma semelhante, os depoimentos mostram falta de preparo para atuar nessa área, tendo em vista questões relacionadas a formação profissional e até mesmo de educação permanente. Limitações nesse campo relacionam-se de forma direta com a atuação profissional. Além do despreparo, outros fatores que comprometem a inclusão de práticas em saúde mental na $A B$ são a falta de interesse dos próprios gestores, desvio das funções da equipe do NASF, e pouco interesse na integração da Rede de Saúde Mental. 
A análise dos dados mostra também que o trabalho em Rede não é desenvolvido no município de forma adequada, e embora Bom Jesus do Itabapoana possua uma equipe de NASF, esta não é destinada ao desenvolvimento do apoio matricial, mas sim atendimentos domiciliares, que possuem uma grande demanda no município. Dessa forma, o NASF não atua como foi idealizado, mas sim, a partir de demandas específicas dos gestores, muitas vezes distantes dos objetivos que direcionaram sua implantação.

As categorias a seguir abordarão detalhadamente as questões acima mencionadas discutindo-as a partir da literatura que fornece embasamento sobre os limites e potencialidades para o desenvolvimento do cuidado em saúde mental. Tal procedimento permitirá compreender como o cuidado em saúde mental vem sendo ofertado no município.

\section{A perspectiva de saúde mental pela ESF}

Inicialmente objetivamos identificar as concepções dos profissionais que atuam nas Unidades de Saúde da Família (USF) sobre o cuidado em saúde mental. Nesse sentido, buscou-se perceber o conhecimento desses profissionais sobre a magnitude da demanda de indivíduos com transtorno mental no território, e ainda quais atividades são destinadas a esses usuários neste primeiro nível de atenção à saúde.

Dados da Organização Mundial da Saúde revelam que a carga das perturbações mentais é grande e está presentes em todas as sociedades ${ }^{7}$. Esses agravos acometem cerca de 450 milhões de pessoas, e apenas a minoria recebe tratamento. Além disso, 0 número de doentes é mais acentuado nos países em desenvolvimento, onde estima-se um aumento desse número em virtude do envelhecimento populacional e condições de vida cada vez piores ${ }^{8}$.

A crescente prevalência de transtornos mentais na população brasileira faz com que a demanda de saúde mental na ESF seja alta e constante, sendo desde usuários com transtorno mental grave ou aqueles dependentes de medicamentos que procuram a Unidade em busca constante troca de receitas controladas e até mesmo aqueles com transtornos mentais comuns ou queixas inespecíficas?.

De acordo com os achados da pesquisa podemos observar um desconhecimento dos profissionais sobre a demanda dos portadores de transtorno mental da área de abrangência e sua responsabilidade sobre ela. Tal aspecto pode gerar desresponsabilização a parcela populacional, já que consideram o CAPS como local destinado ao cuidado adequado, como mostram as falas abaixo:

"Eu não tenho contato, são poucos, os que vêm, vêm mesmo para consulta médico. Eu faço um monte de receita controlada, então eu sei que têm pacientes, mas a maioria é antidepressivo, não é paciente muito grave.

A gente não tem muito contato porque é centralizado, vão todos para o CAPS" (ENF 6).

Os profissionais da $A B$ deveriam desenvolver atividades que favoreçam sua reinserção na sociedade, oferecer orientações e estímulo ao tratamento, os cuidados clínicos, escuta, acolhimento, vínculo, além disso, atividades em grupos que proporcionem a estes usuários um momento para pensar e refletir?.

Com relação às ações em saúde mental desenvolvidas pelos profissionais da ESF, observa-se que são ações ainda centradas na doença, como agendamento/realização de consultas clínicas, encaminhamento e troca de receitas controladas. Por outro lado, ações de promoção e prevenção em saúde mental, como palestras, orientações, educações em saúde e o desenvolvimento da escuta, ainda não são realizadas ou apenas esporadicamente.

"Aqui é mais transcrição de receita, já chegam com um diagnóstico pré-determinado pelo psiquiatra e a gente transcreve algumas receitas, em casos assim muito eventuais eu diagnostico transtorno de ansiedade, transtorno depressivo, mas qualquer coisa mais complicada eu faço a medicação de controle e encaminho para reavaliação do psiquiatra" (MED 3).

Na análise identificou-se que a saúde mental na $A B$ ainda não é desenvolvida com ações que vão ao encontro com o que previa a Reforma Sanitária e Reforma Psiquiátrica, sendo por vezes oferecidas apenas ações rotineiras e superficiais, não atendendo a totalidade das necessidades dos indivíduos que demandam cuidados em saúde mental. A saúde mental não é vista como uma prioridade das ESF, e mesmo sendo o foco da ESF ações de promoção e prevenção à saúde, essas ações para o portador de transtorno mental ainda não são realidades do município. 
Além disso, foram identificadas ações baseadas unicamente na prática médica, sendo a mentalidade dos profissionais voltadas para um cuidado fragmentado em que o CAPS deve realizar as ações e o devido cuidado desses usuários, evidenciado pelo completo desconhecimento dessa demanda em suas áreas de atuação. $O$ fato de muitos profissionais apenas realizarem $\circ$ encaminhamento e apenas algumas medidas, como a troca de receita, se relaciona a situação de que muitos transferem a responsabilidade do cuidado ao CAPS, que também nos leva a perceber uma desresponsabilização em saúde mental.

\section{O preparo dos profissionais da atenção básica para atuar em saúde mental}

Em relação às concepções dos profissionais da ESF sobre usuários que demandam cuidados em saúde mental, objetivou-se identificar como os profissionais da ESF se sentem ao se deparar no seu cotidiano de trabalho com esses usuários. Dessa forma, busca-se perceber o sentimento de preparo para essa atuação.

Cabe a ESF não somente a execução de programas estabelecidos pelo Ministério da Saúde, mas também ações de promoção, prevenção, proteção e reabilitação da saúde mental ao nível de $A B$. No entanto, algumas questões dificultam essa apropriação da ESF com as questões de saúde mental, dentre elas a falta de capacitação ou preparo dos profissionais para atuarem com esses usuários ${ }^{10}$.

Um dos fatores que tornam os profissionais impotentes diante de um caso de saúde mental é à formação de profissionais da área da saúde não ser ainda direcionada para os princípios da Reforma Psiquiátrica, sua história e desafios atuais. Difundir esses valores no meio acadêmico não é muitas vezes prioridade das Universidades, e por isso, formam-se cada vez mais profissionais com sentimento de despreparo na área ${ }^{1}$.

Dessa maneira, a escassez de ações em saúde mental na $A B$ também pode ser resultado de um sentimento de impotência e despreparos destes profissionais nesta área de atuação. A grande parte dos entrevistados declara despreparo para lidar com portadores de transtorno mental, tanto por falta de identificação pela área, ou formação deficiente e principalmente, ausência de capacitações e educação permanente.

"É a única área que eu não me identifico muito, não sei se é por eu não ter muito contato. Eu acho que é mais o despreparo mesmo, eu acho que no geral a equipe de enfermagem é um pouco despreparada, eu acho que há um despreparo até mesmo da equipe médica, já querem encaminhar ao psiquiatra" (ENF 1).

Esse despreparo para atuar em saúde mental que muitos profissionais da $A B$ se referem pode ser oriundo da falta de cursos de capacitação e educação permanente, e acima de tudo pela formação deficiente. Muitas universidades não se encontram voltadas aos princípios da Reforma Sanitária, sua história e desafios atuais. Difundir esses valores no meio acadêmico não é muitas vezes prioridade das Universidades, e por isso, formam-se cada vez mais profissionais com sentimento de incapacidade nessa área ${ }^{11}$.

Durante a realização das entrevistas os profissionais revelaram falta de capacitação por parte da equipe da $A B$. Os entrevistados acreditam que a capacitação para toda equipe seria a melhor forma para que o cuidado em saúde mental fosse consolidado na ESF, como mostram as falas a seguir:

"Acho que uma capacitação para trabalhar como lidar com essas pessoas, igual a gente tem capacitação

de como lidar com a dengue, como lidar com a hanseníase. Acho que falta isso pra toda equipe, porque o manejo é diferenciado. Falta um pouco de conhecimento dentro da área" (ENF 5).

"... falta de treinamento, se fosse 'Vamos fazer uma coisa melhor para o doente mental!', teria que ter um treinamento..." (MED 5).

De uma forma geral podemos assegurar que os profissionais da ESF não se consideram preparados para atuar em saúde mental. Os profissionais revelam a falta de capacitação por parte da equipe, afirmando que para atuarem de forma eficaz com o portador de transtorno mental seria imprescindível um treinamento para que de fato pudessem realizar ações de qualidade direcionadas a esses usuários. A ausência de preparo ou capacitações torna o profissional da saúde impotente para o desenvolvimento de ações em saúde mental, tornando o cuidado 
em Redes de Atenção em Saúde Mental a partir da $A B$ uma diretriz ainda não alcançada no município.

\section{Relações entre CAPS e ESF}

O trabalho em Rede de Atenção em Saúde Mental é uma área da saúde bastante complexa e que exige dos profissionais um preparo adequado. Requer uma parceria e interação com os diferentes setores que envolvem o portador de transtorno mental para que ocorra uma troca de conhecimentos entre os profissionais dos diferentes níveis de atenção, assim como uma co-responsabilização de todos por essa demanda ${ }^{12}$.

A interação com a equipe especializada em saúde mental é fundamental para que a $A B$ desenvolva ações direcionadas a esses usuários. $O$ trabalho integrado dos profissionais da ESF e do CAPS torna-se, portanto, a chave para a efetivação do cuidado integral ao portador de transtorno mental. Entretanto, a pesquisa observou que existe uma falha nesse processo, sendo a articulação entre os profissionais da Rede algo ainda não consolidado.

"A rede eu diria que é um fracasso porque não há uma integração entre a Atenção Básica e o CAPS. Eu acho que ainda o preconceito, as pessoas tem dificuldade de chegar até o CAPS, os profissionais devem achar que os profissionais daqui são doidos também, porque não há esse diálogo, não há essa conversa, só se tiver alguém

quebrando tudo e fugir do controle deles, porque na maior parte das vezes eles não participam o CAPS das dificuldades. Se você perguntar o número por área de

pacientes de saúde mental eles nem respondem essa pergunta, porque é como se a saúde mental não fizesse parte da região deles, de cada PSF" (CAPS 3).

"Paciente com transtorno mental tem muita dificuldade em transitar em qualquer outra unidade que não seja de saúde mental. Em minha opinião a gestão não tem interesse em fazer o paciente do CAPS ir ao PSF, quer mais é que fique concentrado tudo no CAPS, tanto é que você tem um médico atendendo clínica médica aqui dentro, pra que isso? Paciente era para ser atendido lá no PSF. Pirapetinga, Carabuço, distrito pequenininho! Pelo amor de Deus, o pessoal do PSF tem que conhecer todo mundo, aí você chega lá no PSF, você vai falar de um paciente, o PSF não sabe. Ninguém está nem aí, ninguém está nem ai" (CAPS 6).
A percepção geral dos profissionais que atuam no CAPS é que existe uma falha no processo de articulação com os profissionais da $A B$. Essa percepção condiz com o que foi observado, pois não foi possivel identificar ações realizadas em conjunto, nem mesmo uma rotina de reuniões para discussão de casos entre as equipes ou elaboração de ações. Percebe-se um trabalho fragmentado, onde cada setor exerce sua função de forma isolada, com ausência de uma efetiva articulação da Rede de Atenção à Saúde.

Alguns relatos demonstram uma desresponsabilização da $A B$ no que diz respeito ao cuidado do portador de transtorno mental, já que o esses usuários não são assistidos pela ESF, e que cabe ao CAPS toda a responsabilidade de cuidado.

Os entrevistados do CAPS destacam o desconhecimento dos profissionais da $A B$ sobre a demanda de pacientes com transtorno mental, o que é reafirmado nas categorias anteriores. Alguns relatam sentimento de insatisfação com os profissionais da $A B$, que segundo ele, não se interessam pelo cuidado desses indivíduos.

O fato dos profissionais não se responsabilizarem por essa demanda se relaciona a inexistência de um funcionamento em Rede, visto que esse cuidado é destinado ao CAPS, os profissionais da ESF não vivenciam a necessidade de articulação com os demais profissionais em saúde mental.

As visões dos profissionais da ESF são similares aos relatos apresentados pelos profissionais do CAPS. $\mathrm{Na}$ grande parte dos depoimentos, a ausência de articulação foi evidenciada, como mostram as falas abaixo:

"Não ocorre, pode acontecer das enfermeiras, agora eu não tenho contato com ninguém. Aqui o CAPS não é esse daqui não né? $O$ que funciona aqui do lado? De vez enquanto eu vejo eles trabalhando com pacientes psiquiátricos, queria saber o que era, nem isso eu perguntei" (MED 6).

"Até agora não. Nunca precisei graças a Deus" (ENF 10). 
"Uma vez me pediram pra aplicar uma injeção em um paciente do CAPS que mora aqui e eu apliquei, só isso.

Falta de interesse de ambas as partes, de chamar e vamos fazer, acho que é isso" (ENF 14).

"Não temos nenhum vínculo com o CAPS [...] Falta de tempo, falta de trabalho em equipe, a gente não tem"

(ENF 2).

Observa-se a inexistência de articulação entre os profissionais do CAPS e a ESF, fato que vai contra os princípios da reforma sanitária e reforma psiquiátrica. Quanto a realização de atividades desenvolvidas em conjunto, os profissionais às vezes até chegam a mencionar alguma atividade, mas isso não é uma rotina da Rede de Saúde Mental do município, ocorrendo esporadicamente, como por exemplo, quando se tem um caso a ser encaminhado ao CAPS. Também por vezes referiram-se às dificuldades para o trabalho articulado, como sobrecarga do trabalho e falta de interesse por parte de ambas as equipes.

Alguns profissionais ressaltam a importância dessa articulação, por já terem vivenciado essa experiência e saberem o quão benéfico é para o usuário essa interação, embora não tenham experimentado essa realidade no município. Também existem profissionais desconhecem até o local do CAPS, demonstrando um total desinteresse e desarticulação com a Rede de Saúde Mental.

Nesse mesmo sentido, alguns depoimentos revelam a má funcionalidade da Rede como algo que acontece de forma geral na saúde brasileira, manifestando um sentimento de conformidade a essa realidade. Muitos profissionais chegam a afirmar que nunca precisaram dessa interação ou nunca buscaram estabelecer um vínculo mais estreito. Essas concepções apresentam-se em franca contradição com a diretriz que propõe o trabalho em rede como o caminho para se alcançar a integralidade do cuidado, sobretudo em saúde mental, tal depoimento entra em questionamento.

Outro aspecto identificado em relação à percepção dos profissionais sobre o trabalho articulado entre o CAPS e a ESF, relaciona-se ao fato dos profissionais considerarem importante essa prática para o alcance de um cuidado integral ao portador de transtorno mental, conforme mostram os discursos abaixo:
"Muito, muito importante, quando você tem essa parceria, quando você tem um respaldo é uma coisa maravilhosa, é uma coisa que deveria haver em todos os municípios, dessa forma a gente consegue enriquecer muito o tratamento do paciente" (MED 2).

Identificamos que o trabalho direcionado ao portador de transtorno mental no município se dá mediante um cuidado voltado ao modelo biomédico, centrado na doença. Nesse caso, todas as ações à essa demanda são destinadas ao CAPS, nível especializado em saúde mental. As medidas desenvolvidas pela $A B$ são na maioria das vezes inexistentes, ou muito superficiais e esporádicas, evidenciada pela ausência de ações e práticas efetivas voltadas para a promoção e prevenção á saúde, que visem a melhoria da qualidade de vida.

Por outro lado, embora o trabalho em Rede de Atenção em Saúde Mental não seja desenvolvido no município, e por vezes esse trabalho não seja valorizado e priorizado por todos os profissionais que compõem essa rede, a percepção sobre a importância da articulação entre o nível primário e especializado é compreendido por todos.

\section{A responsabilidade do cuidade em saúde mental}

Esta sessão buscou analisar como o CAPS tem atuado no processo de implementação do apoio matricial, se tem trabalhado no sentido de facilitar essa implantação, a fim de identificar se de fato tem trabalhado no sentido de fortalecer a interação entra a saúde mental e a $A B$, e até mesmo se tem assumido seu papel de coordenador dessa rede.

A responsabilidade pelo cuidado ao portador de transtorno mental não se limita ao CAPS, mas envolve toda a rede de saúde mental, o que inclui a $A B$. Fica à responsabilidade do CAPS a coordenação e a organização da demanda e da rede de cuidados em saúde mental no âmbito de seu território segundo a Portaria no 336/0213. No entanto, a grande maioria dos participantes da pesquisa compreende que a responsabilidade ao portador de transtorno mental seja do CAPS, já que este é o Centro especializado ao atendimento ao portador de transtorno mental. Tal concepção está baseada na inexistência de práticas voltadas à esses usuários na $A B$ ou até mesmo pelas inúmeras falhas no que diz respeito ao 
trabalho em redes de atenção à saúde, como inexistência de planos de ações elaborados e executados em conjunto pelas equipes do CAPS e ESF.

"No CAPS tem uma equipe voltada para esse tipo de tratamento. A não ser que aqui fosse uma equipe preparada, existisse uma capacitação para fazer esse acompanhamento, mas como a gente faz vários tipos de atendimentos, seria apenas mais um, não seria um atendimento especializado" (ENF 3).

"Sim, para o CAPS, sempre a gente fala 'esse paciente tem que ser encaminhado para o CAPS'. No CAPS, o cuidado mais adequado" (MED 6).

Os profissionais da ESF no geral relacionam o cuidado em saúde mental ao CAPS, desconsiderando o princípio do trabalho em Rede. Por outro lado, os profissionais do CAPS trazem essa idéia de cuidado compartilhado, como mostram os trechos a seguir.

"Ele é um paciente que precisa ser atendido pela saúde, - CAPS, o PSF, os leitos psiquiátricos, as residências terapêuticas, então acredito que todos devem estar envolvidos nesse tratamento, todos são responsáveis, não só o CAPS" (CAPS 7).

Os profissionais da ESF não se sentem responsabilizados pela demanda de saúde mental, transferindo a tarefa de cuidado ao setor especializado, 0 CAPS. Nesse caso, o cuidado integral não é alcançado, tenho em vista que o cuidado em Redes é a única forma de obtê-lo.

No mesmo sentido o CAPS deve ser o coordenador do cuidado em saúde mental, de forma a assumir um papel mais ativo na articulação entre $a A B$ e a saúde mental ou atuar como ordenador da rede de cuidados. Entretanto, esse papel não tem sido desempenhado de uma forma eficaz, já que a $A B$ não se sente parte integrante da Rede de Saúde Mental. Embora os profissionais do CAPS possuam a percepção da importância do trabalho compartiIhado, não se percebe uma prioridade do CAPS em oferecer apoio, estímulo ou capacitações para que a ESF possa atuar em saúde mental, atuando de forma isolada com comprometimento do trabalho intersetorial.

\section{A atuação do NASF}

A seguir discute-se as percepções dos profissionais tanto do CAPS quanto da ESF em relação a atuação que a equipe do NASF vem desenvolvendo no município, finalizando com as percepções da própria equipe sobre seu trabalho desenvolvido. Acreditase que identificando os conhecimentos de todos esses segmentos, de todos os envolvidos na Rede Atenção à Saúde Mental, os achados poderem ser comparados a fim de se obter uma real análise do trabalho do NASF, e como essa equipe tem atuado no matriciamento, de forma a perceber possíveis questões que limitam tal processo.

NASF foi criado mediante a Portaria GM n ${ }^{\circ} 154$, de 24 de janeiro de 2008, com objetivo de trabalhar de forma conjunta com as equipes da ESF, compartilhando e apoiando suas práticas a fim de potencializar suas ações e aumentar sua resolubilidade. Seu processo de trabalho deve estar sempre voltado ao atendimento compartilhado e interdisciplinar, desenvolvendo estudo e discussão de casos e situações, estabelecendo projetos terapêuticos, orientações e atendimento conjunto que permitem a troca de saberes, capacitação e responsabilidades mútuas $^{14}$.

Tal estratégia recebe o nome de matriciamento, e prevê a capacitação em saúde mental para a ESF e integrá-la com os de mais pontos da rede assistencial, para que a promoção da saúde e reabilitação psicossocial aconteça a partir do nível primário de atenção à saúde. O matriciamento visa, portanto, a desconstrução da lógica dos encaminhamentos do portador de transtorno mental aos níveis especializados para a implantação de um cuidado compartilhado que tem início na $A B$, mas especificadamente na $\mathrm{ESF}^{14}$.

Em relação à percepção dos profissionais que atuam no CAPS, observamos relatos de desconhecimento sobre a atuação dessa equipe no município, o que nos leva a aperceber que $\circ$ trabalho intersetorial não vem sendo desenvolvido, já que os profissionais não trabalham em conjunto. Além disso, muitos profissionais declararam desvios do trabalho do NASF, sendo o trabalho desenvolvido em desencontro que o que é preconizado, como revela os trechos a seguir. 
"Como que o NASF atua no município? É o núcleo de atendimento à saúde? núcleo de apoio? Eu to aqui parada pensando, não conheço muita ação deles, é isso que eu falo com você, na realidade a saúde também fica muito fragmentada, o que acontece num lugar nem sempre é repassado para os outros, então nós somos profissionais do município, de saúde, que desconhecemos algumas atuações da própria saúde, então não é uma coisa alienada? $E$ como que essa alienação pode trazer um benefício, um crescimento, uma melhoria para quem é atendido? A eficácia é pouca" (CAPS 2).

"Fazendo serviço de home care (risos). Hoje o NASF faz um serviço que vai além do serviço deles, então não há isso, não há orientação familiar, há um atendimento particular, domiciliar" (CAPS 3).

"Inclusive tive uma reunião com o pessoal da secretaria do Estado e cheguei a perguntar o que era - NASF, pois é mais um setor que não está muito bem esclarecido. Cada município traça uma estratégia para - NASF. Eu posso falar verdade aqui com você? É cabide de emprego, não funciona, não tem um objetivo claro em minha opinião" (CAPS 6).

O NASF por vezes desenvolve um trabalho que pode ser caracterizado como um desvio de função, pois realiza atividades demandadas pelos gestores locais, que não estão contempladas em suas diretrizes. No município de Bom Jesus, pela carência de muitos dispositivos de saúdes e especialidades, a equipe do NASF fica encarregada, na maior parte das vezes, de desenvolver consultas domiciliares, por isso seu trabalho é nomeado por muitos profissionais como Home Care.

Já com relação às entrevistas dos profissionais da $E S F$, observamos que a equipe do NASF desenvolve um trabalho domiciliar e até mesmo nas ESF que contribui com a saúde da população, o que justifica serem bem vistos por uma grande parte dos profissionais da ESF. Entretanto, sabe-se que existe uma outra atribuição desses profissionais que não tem sido realizada na maior parte das vezes, tanto pela intensa demanda por esses atendimentos quanto pelo número de profissionais e número de equipes para atender todo município e distritos.

"Aqui eles vieram pra somar. Aqui tem atendimento de psicólogo, nutricionista, assistente social, fonoaudiólogo..." (ENF 6).
"Até onde eu sei o NASF não é realmente o NASF idealizado. Aqui não existe aquela Unidade do NASF, - município aproveita aquele profissional que está contratado para o NASF e o lança para os buracos de outros profissionais, uma vez por semana vem nutricionista e ela vai migrando. Não existe aquela interação idealizada bonitinha não" (MED 5).

Observamos que a prática do apoio matricial, foco do NASF, não tem sido de fato uma prioridade no município, mas sim atendimentos individualizados, que trás benefícios à saúde da população, mas não contempla sua real proposta e compromete a rede de atenção à saúde mental.

Além da percepção dos profissionais do CAPS e da ESF sobre a atuação do NASF no município, é importante também identificar a percepção que a própria equipe do NASF possui sobre o trabalho que têm desenvolvido no município. De acordo com os relatos a seguir, podemos observar que a atividade mais desenvolvida pela equipe é o atendimento em domicílio, outra atividade são palestras nas ESF, mas esta atividade não é desenvolvida por toda equipe.

"O NASF não faz aquilo que deveria ser feito, a gente faz atendimentos individuais, os emergenciais, os pacientes domiciliados, os acamados. Todos os pedidos, as solicitações que vem do ministério público o NASF que atende" (NASF 4).

Todos os profissionais que compõem essa equipe revelam atuar na maior parte das vezes de forma individualizada, sendo as ações em equipe algo esporádico, sendo possível identificar relatos até mesmo de desconhecimento sobre a atuação profissional entre os membros da equipe. Dessa maneira, o trabalho interdisciplinar perde seu foco, e ganha ênfase uma atuação voltada para profissional-paciente, onde cada profissional, dentro da sua especialidade, realiza seus atendimentos tanto nas ESF quanto nos domicílios.

"A gente trabalha mais individualmente. Enquanto acontecem palestras, alguns programas, a gente trabalha em equipe, mas no geral não trabalhamos em equipe, a gente trabalha de forma individualizada, de acordo com as necessidades específicas de cada paciente" (NASF 1). 
Ainda com relação a percepção da equipe do NASF sobre o trabalho desenvolvido, é importante destacar que a equipe também relata desvios do trabalho, o que de fato compromete sua real função e execução de práticas que deveriam ser realizadas mas não podem ser executadas pela intensa demanda de atendimentos que são destinados a estes profissionais.

"Por mais que você queira orientar você não tem tempo, você tem tanto atendimento que você não tem tempo para orientação. É um caso a ser discutido com toda equipe, ver realmente a necessidade das palestras e dos atendimentos. Só que o município não tem condições de ter quatro fonoaudiólogos, cinco ou seis fisioterapeutas no NASF para dar assistência ao município e aos distritos, então como a gente fica? Atendendo" (NASF 2).

Os depoimentos dos profissionais que atuam no CAPS, na ESF e na própria equipe do NASF sobre sua atuação no município revelam que o cuidado em saúde mental, está sendo realizado sobre a forma de atendimentos clínicos, voltados para a prática curativa, sobretudo na forma de atendimentos domiciliares, sendo outras atividades, como de prevenção a saúde, capacitação da $A B$ e o matriciamento, não priorizadas.

Acredita-se que essa atuação do NASF compromete a funcionalidade da Rede de Atenção à Saúde Mental, já que esta equipe deveria estar desenvolvendo sua articulação, para que o portador de transtorno mental pudesse ter acesso não somente ao CAPS, mas todo cuidado que a $A B$ pudesse proporcionar a ele. Por outro lado, o que se observa é uma saúde fragmentada, em que o NASF deixa de assumir seu papel para suprir outras demandas do município.

\section{Apoio matricial em saúde mental}

Por fim, objetivou-se analisar o apoio matricial em saúde mental no município, de forma a identificar a percepção de todos os profissionais que compõem a Rede de Saúde Mental sobre a atuação do NASF como mediador entre a $A B$ e o CAPS.

NASF é uma equipe formada por profissionais de diferentes áreas do conhecimento para atuar de forma conjunta com a equipe de ESF. Esse dispositivo ainda não é realidade de muitos municípios, já outros que já os dispõem, muitas vezes não funcionam como o articulador entre a Saúde Mental e a $A B^{15}$.

Deve atuar no matriciamento em saúde mental, ou seja, proporcionar uma articulação entre a Saúde Mental e a $A B$, favorecendo a trocas de saberes entre os profissionais, o cuidado compartilhado entre as equipes, uma corresponsabilização e, principalmente, de uma atenção mais humanizada ao portador de transtorno mental ${ }^{15}$.

Esta categoria tem por objetivo identificar se o NASF tem sido de fato um mediador entre a ESF e o CAPS. Muitos profissionais da ESF negam a atuação do NASF como um facilitador da integração entre os profissionais da $A B$ e do CAPS.

"A gente não teve esse caso ainda, que precisasse do NASF ou que precisasse ter essa interação com CAPS" (ENF 1).

"Não, que eu tenha conhecimento não, você pode ver com a enfermeira, porque às vezes a enfermeira tem esse contato com eles, eu, médica aqui na unidade não tenho tido essa interação" (MED 5).

Alguns profissionais do CAPS desconhecem a atuação do NASF, e a parte que possuem esse conhecimento declara que a equipe não desenvolve o trabalho de integrar os profissionais da rede de saúde mental, desenvolvendo no município outro trabalho, mas o exercício de fortalecer a Rede de Saúde Mental ainda não é objetivado.

"Não, nada, NASF nem sabe que CAPS existe, nem sabe o que faz parte da equipe CAPS" (CAPS 3 ). "NASF resolve muito bem a demanda da atenção básica. Aqui no município eu vejo o NASF atuando muito com a atenção básica, agora interação com o CAPS nunca vi, nunca vi" (CAPS 6).

Embora a maioria dos profissionais que atuam na ESF e os profissionais do CAPS que foram aptos a descrever o trabalho do NASF no município terem negado essa atuação da equipe como facilitador da integração da rede de atenção em saúde mental, os membros da equipe do NASF afirmam tal função. 
"É um paciente que a gente enxerga que não está legal, que precisa de um exame complementar, a gente encaminha. A gente encaminha sempre, tanto para psiquiatra quanto para psicólogo, então a gente sempre tenta correlacionar os profissionais da rede, isso acontece bastante" (NASF 1).

"Eu acho que o NASF contribui uma vez que ele muitas vezes ajuda a direcionar, é o sistema de referencia e contra referencia mesmo" (NASF 7).

Embora os entrevistados afirmem interação com a equipe de saúde mental, suas falas remetem ao cuidado voltado para a prática do encaminhamento, do sistema de referência e contra-referencia, ao contrário do que prevê a Reforma Psiquiátrica, que seria um trabalho compartilhado por uma Rede de Atenção a Saúde, com a co-responsabilidade e cuidado mútuo de todos os setores que envolvem essa Rede, a fim de se alcançar um cuidado que contemple o indivíduo como um todo, nas suas múltiplas dimensões.

Entende-se que os profissionais não compreendem a importância de um cuidado integral alcançado pela integração entre a $A B$ e a saúde mental, sobretudo com intermédio de uma equipe que trabalhe em prol de facilitar essa articulação entre os profissionais, o NASF. Em contrapartida, acreditam que a integração se faz a partir dos encaminhamentos. Essa concepção faz com que ofereçam um cuidado fragmentado e baseado nas especialidades médicas. Dessa forma, embora afirmem a atuação de facilitar a integração entre a saúde mental e a $A B$, os profissionais não demonstram em suas falas um real conhecimento sobre como se consiste o trabalho integrado em Rede de Saúde.

Ainda com relação à percepção do NASF sobre sua atuação como mediador entre a ESF e o CAPS, identificou-se algumas falas desses profissionais que nos levam a reflexão sobre a integração que esses profissionais possuem com toda a rede e sua participação no desenvolvimento de articulação, sobretudo entre o CAPS e a ESF. Observa-se que nem sempre essa integração ocorre de forma rotineira, e que ainda alguns profissionais negam essa integração e acreditam que isso ainda é de fato um ponto a ser melhorado a fim de garantir uma melhoria do cuidado, sendo está a única forma de se obter um cuidado integral ao portador de transtorno mental.
"Eu acho que com um pouco de dificuldade, acredito que em alguns casos ocorre sim, quando ha necessidade, não é uma coisa que acontece sempre, não é uma dinâmica, mas uma coisa que ocorre quando precisa" (NASF 3).

"Eu acho que está um pouco falho, das duas partes, talvez pela correria do dia a dia. Ontem mesmo nossa segunda reunião, nós estamos tentando montar um trabalho em redes, por duas vezes nós convidamos os profissionais do CAPS e eles não puderam comparecer" (NASF 4).

Observamos nessa categoria uma divergência entre as percepções das diferentes equipes, não há uma homogeneidade nos pensamentos com relação à atuação do NASF e o apoio matricial em saúde mental no município. Embora de uma forma geral os profissionais do NASF acreditem estar atuando nessa função, muitos profissionais da ESF desconhecem ou negam o desempenho dessa atividade, assim como os profissionais do CAPS.

Mesmo com relatos dos profissionais da ESF que afirmam atuação do NASF como um facilitador da integração entre os profissionais da $A B$ e do CAPS, não justificam com ações em que seja visível realmente essa atuação do NASF. Por outro lado, os profissionais do CAPS que declaram conhecer a atuação do NASF negam esse papel da equipe, demonstrando um descontentamento no que diz respeito ao apoio oferecido pela equipe do NASF em saúde mental.

Interessante destacar ainda que mesmo com os profissionais do NASF afirmem atuar como mediadores entre os profissionais do CAPS e ESF, revelam muitas vezes a inexistência da interação entre os demais profissionais da Rede.

\section{Considerações finais}

Mesmo com os avanços já obtidos após a Reforma Psiquiátrica, muitas dificuldades ainda atingem 0 portador de transtorno mental. $O$ que se espera é que ele seja assistido em todos os segmentos da Rede de Atenção a Saúde, com uma co-responsabilização de todos os setores, entretanto, o que se observa é que essas ações em saúde mental na $A B$ 
estão aquém do que realmente poderia proporcionar a esses indivíduos.

$A A B$, embora destinada a ações de promoção e prevenção à saúde, ainda não desenvolve ações com essas finalidades ao público que demanda cuidados em saúde mental. Com relação às ações em saúde, percebemos que ainda estão baseados na prática da medicalização, e encaminhamentos, estando a saúde mental do município voltada para o modelo biomédico, centrado na cura.

O cuidado ao portador de transtorno mental ainda enfrenta entraves que impossibilitam que esse cuidado aconteça a partir da AB. Um desses desafios consiste no sentimento de despreparo dos profissionais para atuar em saúde mental, tendo em vista uma carência em cursos de capacitação e ausência de educação permanente.

Para o desenvolvimento de ações em saúde mental na $A B$, além do preparo oriundo de capacitações e educação permanente, a interação com a equipe especializada em saúde mental do município é fundamental, e os achados da pesquisa nos mostram que essa interação ocorre apenas esporadicamente ou através de encaminhamentos. No entanto, uma interação que garanta um cuidado integral, com ações e cuidados compartilhados entre a Rede não foi evidenciada na pesquisa.

Uma importante estratégia para se obter a integração da Rede é através do trabalho do NASF, uma equipe destinada à garantir a aproximação entre os profissionais do CAPS e da $A B$, correlacionar esses setores, e inclusive capacitar as equipes de $A B$ para que a atuação em saúde mental. No entanto, essa equipe vem atuando priorizando atendimentos individualizados nas USF e nas residências da população.

Observa-se também uma falha no que diz respeito a coordenação da Rede a partir do CAPS. O Centro Especializado deveria assumir a responsabilidade de coordenar toda Rede, criar estratégias para fortalecê-la e priorizar a articulação entre os diversos profissionais. Entretanto, o que se observa é um trabalho fragmentado, em que o CAPS não objetiva essa articulação como algo prioritário para o cuidado ao portador de transtorno mental.
Ressalta-se a necessidade da conscientização dos profissionais e gestores sobre a importância de uma Rede de Atenção à Saúde Mental que atue de forma articulada e integrada. Além dessa, outras medidas são fundamentais, tais como capacitação na forma de educação permanente para todos os níveis de atenção a saúde, e implantação do apoio matricial por parte da equipe do NASF.

Por fim, concluímos que a busca por um novo modelo de cuidados no campo da saúde mental deve ter como base uma mudança na prática do cuidado. Este, precisa deixar de ser limitado a tratamentos medicamentosos e reabilitação, se transformando em um modelo que possibilite o cuidado integral ofertado por uma Rede de Serviços de Saúde. Tal cuidado deve se iniciar na $A B$ com ações de promoções à saúde e se estender nos demais níveis de atenção. Nesse sentido, para que a Reforma Psiquiátrica seja alcançada é fundamental a desconstrução de muitas concepções e práticas que permeiam tanto a sociedade, quanto profissionais e gestores de saúde.

\section{Contribuição dos autores}

Borges NS: Realizou a dissertação de mestrado, a qual foi a base para o artigo. Atuou no planejamento e desenvolvimento da pesquisa, realizou a coleta e análise dos dados, assim como a redação do artigo. Teixeira LA: Orientador da dissertação de mestrado. Atuou no planejamento e concepção do estudo, orientou a coleta e a análise dos dados. Realizou a correção do artigo.

\section{Conflitos de interesses}

Nenhum conflito financeiro, legal ou político envolvendo terceiros (governo, empresas e fundações privadas, etc.) foi declarado para nenhum aspecto do trabalho submetido (incluindo mas não limitandose a subvenções e financiamentos, participação em conselho consultivo, desenho de estudo, preparação de manuscrito, análise estatística, etc.).

\section{Referências}

1. Foucault M. Microfísica do Poder. 20.ed. Rio de Janeiro: Graal; 1979.

2. Amarante PDC. Saúde mental, Desinstitucionalização e Novas Estratégias de Cuidado. In: Giovanella L. et al (Orgs.). Políticas e sistema de saúde no Brasil. Rio de Janeiro: Fiocruz, 2008. p. 735-759. 
3. Nunes $M$, Jucá VJ, Valentim CPB. Ações de saúde mental no Programa Saúde da Família: Confluências e Dissonâncias das Práticas com os Princípios das Reformas Psiquiátrica e Sanitária. Cad Saúde Pública. 2007;23(10):2375-2384. doi: $10.1590 /$ S0102-311X2007001000012

4. Jorge MAS, Carvalho MCA, Silva PRF. Políticas e Cuidado em Saúde Mental. Contribuições para a prática profissional. Rio de Janeiro: Editora Fiocruz; 2014.

5. Brasil. Ministério da Saúde. Secretaria de Atenção à Saúde. Departamento de Atenção Básica. Saúde mental / Ministério da Saúde, Secretaria de Atenção à Saúde, Departamento de Atenção Básica, Departamento de Ações Programáticas Estratégicas. Brasília: Ministério da Saúde; 2013.

6. Bardin, L. Analise de Conteúdo. 3.ed. Lisboa: Edições 70; 1977.

7. Organização Mundial de Saúde. Integração da saúde mental nos cuidados de saúde primários: Uma perspectiva global. [Internet]. 2009. Disponível em: https://www.who. int/eportuguese/publications/Integracao_saude_mental_ cuidados_primarios.pdf

8. Organização Mundial de Saúde. Relatório Mundial de Saúde. Saúde mental: nova concepção, nova esperança. [Internet]. 2002. Disponível em: https://www.who.int/ $\mathrm{whr} / 2001 /$ en/whrO1_dimessage_po.pdf

9. Gonçalves DA, Ballester D, Chiaverini DH, Tófoli LF, Chazan LF, Almeida $\mathrm{N}$ et al. Guia prático de matriciamento em Saúde Mental. Brasília: Ministério da Saúde, Centro de Estudos e Pesquisa em Saúde Coletiva; 2011.

10. Oliveira FB, Guedes HKA, Oliveira TBS, Silva JCC. Saúde Mental e Estratégia de Saúde da Família: Uma Articulação Necessária. Psychiatry Online Brasil. 2009;14(9).

11. Nunes MO, Campos RO. Prevenção, Atenção e Controle em saúde mental. In: Paim JS, Almeida N. Saúde Coletiva: Teorias e Práticas. Rio de Janeiro: MedBook; 2014.

12. Gazignato ECS, Silva CRC. Saúde Mental na Atenção Básica: $O$ trabalho em Rede e o Matriciamento em Saúde Mental na Estratégia de Saúde da Família. Saúde Debate. 2014;38(101):296-304. doi: 10.5935/01031104.20140027

13. Brasil. Ministro da Saúde. Portaria $n^{\circ} 336$, de 19 de fevereiro de 2002.

14. Brasil. Ministério da Saúde. Secretaria de Atenção à Saúde. Departamento de Atenção Básica. Diretrizes do NASF: Núcleo de Apoio a Saúde da Família. Brasília: Ministério da Saúde; 2010.

15. Machado DKS, Camatta MW. Apoio matricial como ferramenta de articulação entre a saúde mental e a atenção primária à saúde. Cad Saúde Colet. 2013;21(2):224-32. 